\title{
Development of Water Flowing Fractured Zone Caused by Fully Mechanized Top Coal Caving in Xin'an Coal Mine
}

\author{
Changxiang Wang \\ Corresponding author \\ State Key Laboratory of \\ Mining Disaster Prevention \\ and ControlCo-founded by \\ Shandong Province and the \\ Ministry of Science and Technology \\ Shandong University of Science and \\ Technology \\ Qingdao, China \\ 1554624100@qq.com \\ Buchu Zhang \\ State Key Laboratory of \\ Mining Disaster Prevention \\ and ControlCo-founded by \\ Shandong Province and the \\ Ministry of Science and Technology \\ Shandong University of Science and \\ Technology \\ Qingdao, China \\ 525047249@qq.com
}

\author{
Ning Jiang \\ Corresponding author \\ State Key Laboratory of \\ Mining Disaster Prevention \\ and ControlCo-founded by \\ Shandong Province and the \\ Ministry of Science and Technology \\ Shandong University of Science and \\ Technology \\ Qingdao, China \\ jiangning198961@163.com \\ Wenbo Wang \\ State Key Laboratory of \\ Mining Disaster Prevention \\ and ControlCo-founded by \\ Shandong Province and the \\ Ministry of Science and Technology \\ Shandong University of Science and \\ Technology \\ Qingdao, China \\ wangwenbo5211314@qq.com
}

\author{
Yao Lu \\ State Key Laboratory of \\ Mining Disaster Prevention \\ and ControlCo-founded by \\ Shandong Province and the \\ Ministry of Science and Technology \\ Shandong University of Science and \\ Technology \\ Qingdao, China \\ 723262355@qq.com \\ Chuanping Sun \\ State Key Laboratory of \\ Mining Disaster Prevention \\ and ControlCo-founded by \\ Shandong Province and the \\ Ministry of Science and Technology \\ Shandong University of Science and \\ Technology \\ Qingdao, China \\ 545236818@qq.com
}

\begin{abstract}
Taking Xin'an coal mine as an example, through empirical formula, regional analogy, theory analysis and analog simulation experiment, predicted the high of water flowing fractured zone under the condition of fully mechanized top coal caving, used monitoring system to measure the height of water flowing fractured zone on site, confirmed the rationality of the theoretical analysis. Through the specially experimental box, a simulation material of top coal caving has been developed to simulate the characteristics of water flowing fractured zone under fully mechanized caving mining condition: The caving zone develops rapidly, and the overall growth is approximately linear. The development of fractured zone showed a staged linear growth. It is found that both the empirical formula calculation and the analogical prediction result include the measured results. The prediction is basically accurate, but the accuracy is not high and the error is relatively large. Only the theoretical analysis combined with the theory of relevant rock pressure and the specific formation conditions of coal mine is accurate.
\end{abstract}

Keywords-fully mechanized top coal caving, water flowing fractured zone, height prediction, top coal caving simulation material, developmental characteristics

\section{INTRODUCTION}

Since the Xin'an coal mine was put into operation, the fully mechanized top coal caving technology has widely used to mine $3 \#$ coal with the thickness of $8 \mathrm{~m}$. Compared with the layered mining, the mining of thick coal seam of fully mechanized top coal caving mining has greatly reduced the excavation rate of roadway and improved the yield per unit area. On the other hand, fully mechanized top coal caving has serious damage to overburden. The coal strata of Xin'an coalfield are generally covered by thick Quaternary, and it is also threatened by the aquifer at the bottom of the Quaternary system by adopting the fully mechanized top coal caving mining technology in the shallow part. For this reason, Xin'an coal mine urgently needs to study the failure and movement law of overburden under fully mechanized top coal caving mining.

The prediction of the water flowing fractured zone is the key to mine water control project. In order to explore the development regularity of the water flowing fractured zone, many scholars have made outstanding contributions. Academician Liu[1-2] obtained the calculation formula of the water flowing fractured zone development height by statistics, and met the early majority design requirements of mine water mining. However, in the background of new mining technology, the error of this method is getting bigger, and predicting the development height of water flowing fractured zone which is more suitable for mining technology and is easy to operate has become one of the most important research topics for mining workers.

With the development of coal mining technology, more and more theories are applied to predict the water flowing fractured zone. Professor Xu et al[3-4] put forward a new method to predict the height of water flowing fractured zone through the key strata location of overburden rock on the basis of the key strata theory. According to the failure characteristics of different lithologic strata and the analysis of rock bearing capacity, deformation ability and the variation of overburden physical quantity in mining process, Professor Wang et al[5] presented a mechanical model for predicting the height of water flowing fractured zone. Huang et al[6] 
put forward a new method for predicting the height of water flowing fractured zone based on overburden combination structure and strata tensile deformation calculation. According to the system theory, Zhang et al[7] create a mining system which takes the mining system ( mining system + mining coal seam ) and the driven body ( mining cover rock) as a whole. The uncertainty of the traditional prediction method and the complexity of the theoretical study are avoided. In order to accurately predict the height of water flowing fractured zone of mining overburden, Chai et al[8] chose mining thickness, ratio coefficient of hard rock lithology, inclined length of working face and mining depth as the main influencing factors of development height of water flowing fractured zone of mining overburden rock, combined with 48 groups of measured data. Using support vector machine regression (SVR) and genetic algorithm (GA) to optimize the parameters, a prediction model of the height of water flowing fractured zone of mining overburden rock based on GA-SVR is established. Other scholars have also carried out useful research[9-12].

The author also conducted a related study[13-14], this paper will be integrated with a variety of methods to predict the water flowing fractured zone height of specific conditions, through the preparation of similar simulated materials to simulate fully mechanized caving mining, the development characteristics of water flowing fractured zone under specific conditions are given.

\section{Mining TECHNOLOGY AND GEOLOGICAL BACKGROUND}

Above the Midwest of Xin'an coal mine is the Weishan Lake, Dushan Lake and Zhaoyang Lake, the field within the Quaternary containing multi-layer water-bearing sand layer, there is a multi-layer water-resisting layer between the water-bearing sand layers, especially the middle of the Quaternary water-resisting layer, thickness $19.00-54.50 \mathrm{~m}$. Clay plasticity is strong, better water barrier performance, and widely distributed area.

Xin'an coal mine used underground mining methods, shaft and downhill longwall coal mining methods, roof caving method, mining level of $-300 \mathrm{~m}$, fully mechanized top-coal caving technology. The main mining coal seam is the $3_{\text {lower }}$ coal of Shanxi group with $8 \mathrm{~m}$ thick, simple structure, occasionally a layer of mudstone stone, is a relatively stable coal seam. The working face is $802 \mathrm{~m}$ long, the slope is about $96-156 \mathrm{~m}$ long, the dip angle of coal seam is about $6^{\circ}$, and the thickness of mining is $8 \mathrm{~m}$. Xin'an coal mine drilling strata simplified in Table I.

TABLE I. XIN'AN COAL MINE DRILLING STRATIFICATION SUMMARY TABLE

\begin{tabular}{|c|c|c|c|c|}
\hline Stratum & Rock name & Lithology description & Thickness/m & Depth/m \\
\hline \multirow{2}{*}{ Quaternary } & coreless drilling & loose layer & 90.02 & 90.02 \\
\hline & clay, clay containing sand, clay containing fine sand & water-resisting layer & 44.98 & 135.00 \\
\hline \multirow{3}{*}{ Jurassic } & siltstone & medium hard rock & 21.30 & 156.30 \\
\hline & mudstone & soft rock layer & 26.00 & 183.30 \\
\hline & fine sandstone & hard rock layer & 15.27 & 198.57 \\
\hline \multirow{5}{*}{ Permian } & siltstone & medium hard rock & 5.75 & 204.32 \\
\hline & fine sandstone & hard rock layer & 7.16 & 211.48 \\
\hline & mudstone & soft rock layer & 10.52 & 222.00 \\
\hline & siltstone & medium hard rock & 8.93 & 230.93 \\
\hline & 3 coal & soft rock layer & 9.26 & 240.19 \\
\hline
\end{tabular}

\section{STOPE ROOF MECHANICAL TEST}

The drilling coring is subjected to mechanical testing to test the mechanical parameters of the roof. Due to the part soft rock sample and limited number of rock samples, part of the rock samples can not be processed into a standard sample, but all the sample numbers are generally not less than 3 , and all rock samples are naturally water-bearing, and part of the formed coal rock mass sample is shown in Fig. 1 .

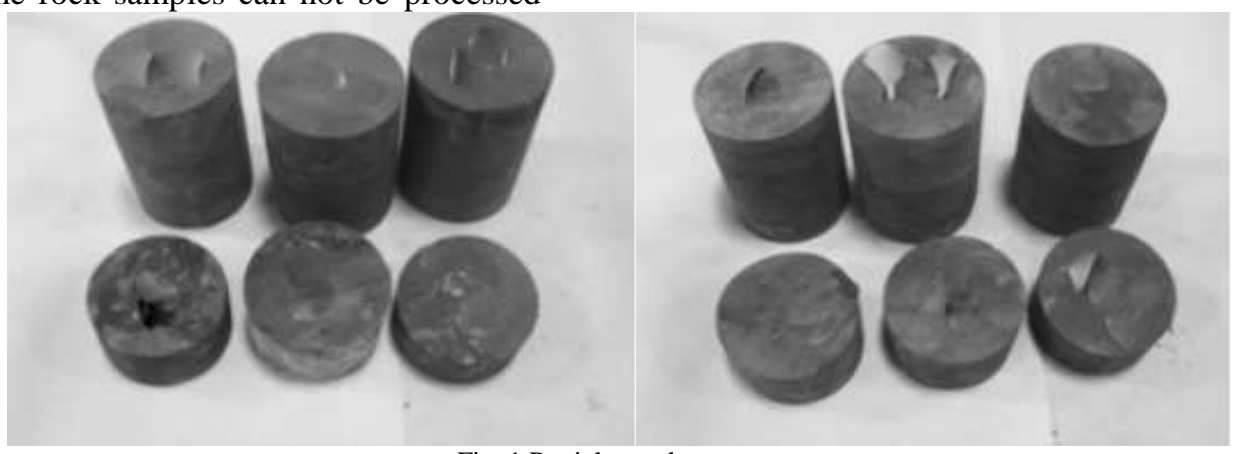

Fig. 1 Partial samples

As the size of part of the rock specimen is not a standard specimen, according to the Test Specification, 
the standard specimen with a height to diameter ratio of 2 , the test results for non standard specimens are converted to the standard size strength by the next formula:

$$
\sigma_{C}=\frac{\sigma_{L}}{1.125(0.778+0.222 D / L)}
$$

Where $\sigma_{L}$ is the strength of non-standard specimens,
$\mathrm{MPa} ; \sigma_{C}$ is the converted into standard specimen compressive strength, $\mathrm{MPa} ; \mathrm{D}$ is the diameter of non-standard specimens, $\mathrm{cm}$; $\mathrm{L}$ is the height of non-standard specimens, $\mathrm{cm}$.

The mechanical tests of coal and rock samples are carried out by MTS test machine, and the test results of physical and mechanical parameters are shown in Table II.

TABLE II. EXPERIMENTAL RESULTS OF PHYSICAL AND MECHANICAL PARAMETERS OF COAL AND ROCK

\begin{tabular}{|c|c|c|c|c|c|}
\hline Rock type & $\begin{array}{c}\text { Tensile strength } \\
\text { /MPa }\end{array}$ & $\sigma_{C} / \mathbf{M P a}$ & $\begin{array}{c}\text { Modulus of } \\
\text { elasticity /GPa }\end{array}$ & $\begin{array}{c}\text { Cohesive } \\
\text { strength } / \mathrm{MPa}\end{array}$ & $\begin{array}{c}\text { Internal } \\
\text { friction angle/ }{ }^{\circ}\end{array}$ \\
\hline \multirow{2}{*}{ hard rock } & $5.86 \sim 9.19$ & $58.1 \sim 95.1$ & $15.5 \sim 25.8$ & $7.2 \sim 10.1$ & $28.2 \sim 31.1$ \\
\hline & 8.29 & 78.8 & 20.4 & 9.2 & 30.5 \\
\hline \multirow{2}{*}{ medium hard rock } & $2.26 \sim 8.51$ & $35.1 \sim 49.1$ & $8.2 \sim 11.9$ & $5.5 \sim 8.9$ & $26.8 \sim 29.1$ \\
\hline & 5.75 & 43.9 & 9.6 & 7.2 & 27.9 \\
\hline \multirow{2}{*}{ Soft hard rock } & $0.21 \sim 0.72$ & $11.8 \sim 17.1$ & $4.5 \sim 8.9$ & $2.2 \sim 4.3$ & $20.2 \sim 24.5$ \\
\hline & 0.49 & 14.4 & 6.4 & 2.7 & 22.8 \\
\hline
\end{tabular}

\section{HEIGHT PREDICTION OF WATER FLOWING FRACTURED ZONE}

\section{A. Empirical prediction}

Although there is no practical calculation formula for the height of overburden failure of fully mechanized top coal caving in thick coal seam, but the calculation according to the Three down procedures still has a certain reference significance, according to the type of hard overlying rock overcracking damage to the structure of the fracture zone with a height formula[1-2]:

$$
H_{d}=\frac{100 M}{1.2 M+2} \pm 8.9, \text { or } H_{d}=30 \sqrt{\sum M} \pm 10
$$

Where $M$ - mining thickness, m; $\sum M$ - mining thickness, $\mathrm{m}$.
Fully mechanized top coal caving thickness calculated by $8 \mathrm{~m}$, the height of water flowing fractured zone is calculated by the above formula: $H_{d}=60.1 \sim 77.9 \mathrm{~m}$, or $H_{d}=74.9 \sim 94.9 \mathrm{~m}$.

In the adjacent area of the mine, due to the continuous formation, and then select the mine with roughly the same mining technology background, the water flowing fractured zone height also has a great reference significance, so the statistics of Zaozhuang, Jining and other adjacent parts of the mine water flowing fractured zone development as shown in Table III[15-17], analogy derived Xin'an coal mine water flowing fractured zone height: $H_{d}=(9.5 \sim 13.6) \sum M=76 \sim 108.8 \mathrm{~m}$

TABLE III. NEAR THE COAL MINE WATER FLOWING FRACTURED ZONE DEVELOPMENT STATISTICS

\begin{tabular}{cc}
\hline Mine name & Rock formation \\
\hline Yangcun mine & siltstone, mudstone, limestone \\
Jiangzhuang mine & limestone, siltstone, mudstone \\
Suncun Mine & sandstone \\
Xinglongzhuang mine & sandstone, mud limestone, shale \\
Chaili coal mine & limestone, siltstone, mudstone
\end{tabular}

\section{B. Theoretical analysis prediction}

According to the theory of rock pressure[18], the combination of rock formation and rock physical properties determines the motion and stability of the overlying strata affected by mining. Due to different lithology of Xin'an coal mine, the rock layer will damage from bottom to top layer. Due to near the stope, affected by mining, and there is no thick hard rock, under the condition of fully mechanized mining for $8 \mathrm{~m}$, Permian strata is bound to destroy and form a water fracture zone. According to the theory of the key layer, it can be seen that the fine sandstone and siltstone of the Jurassic are two critical hard rock layers, and the minimum ratio of split is 9.5, However, the top of the Jurassic fine sandstone to the top of the stope is $45.75 \mathrm{~m}$, thus calculated the split ratio is 5.7, the greater the disparity, it is inferred that the rock will be broken, the formation of hydraulic fissure zone.

The fine sandstone and siltstone of Jurassic are separated by a layer of soft rock and mudstone in the middle of the system, which can limit the development of the water flowing fractured zone, but it has been calculated that the ratio of crack to production between the top of the Jurassic fine sandstone and the top of the stope is 5.7, which shows a wide gap. Compared with hard rock, soft rock can only play a greater role in absorbing the loss of splitting energy, that is, to prevent the fracture to the higher rock formation, but can not prevent the occurrence of cracks, so the mudstone itself will produce cracks and damage. The thickness of the top of the Jurassic mudstone to the top of the stope is $73.63 \mathrm{~m}$, and the split ratio is 9 , which is close to the minimum value of the adjacent mining area. The upper part of the 
mudstone is the hard rock layer, which is more effective than the soft rock to break the fracture development, it is inferred that the water conduction fracture zone will terminate at the top of the Jurassic mudstone, near the bottom of the Jurassic siltstone.

\section{Similar simulation prediction}

1) The development of fully mechanized top coal caving material

In order to simulate the effect of fully mechanized caving, the thickness of coal seam is divided into two parts, one is the thickness of bottom coal $(2 \mathrm{~m})$, the other is the thickness of top coal $(6 \mathrm{~m})$. Normal laying of similar simulated material in bottom coal thickness, Laying a mixture of coal gangue, sand and calcium carbonate with a certain strength within the thickness range of caving coal, after mining the coal seam at the bottom, the top coal can collapse under the action of self-weight, simulating the caving effect of the top coal, after the top coal collapses, clear out the mining space quickly.

In order to obtain a mixture of coal gangue, sand and cement with reasonable strength, a small experimental box[19] was made to simulate the collapse time of the mixture under different ratios, and the particle size of the coal gangue was between $5-10 \mathrm{~mm}$. Because the ratio of the binder of common similar materials is about $10 \%$, the ratio of the designed mixture is shown in Table IV.

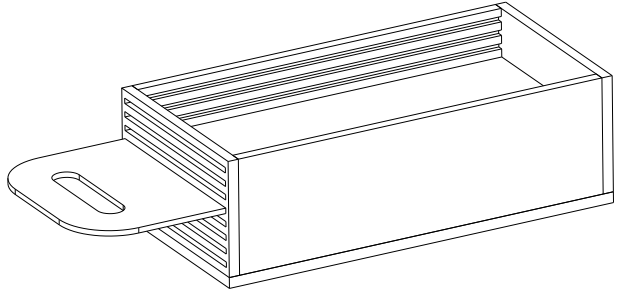

(a) Design diagram

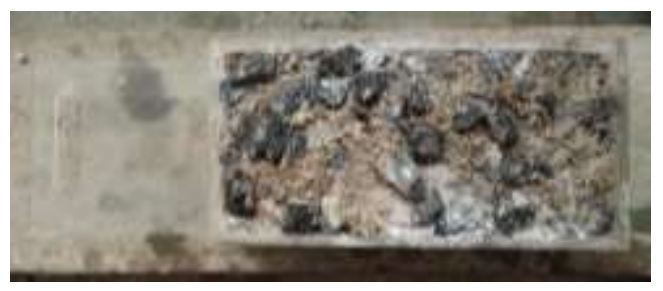

(b) Physical drawing

Fig 2 Experimental box

TABLE IV. TENSILE STRENGTH TEST RESULTS OF SIMILAR MATERIALS

\begin{tabular}{|c|c|c|c|c|c|c|c|}
\hline $\begin{array}{l}\text { Specimen } \\
\text { number }\end{array}$ & $\begin{array}{c}\text { Matching } \\
\text { number }\end{array}$ & $\begin{array}{c}\text { Initial collapse } \\
\text { time } / \mathrm{min}\end{array}$ & $\begin{array}{c}\text { Periodic } \\
\text { collapse } \\
\text { time/min }\end{array}$ & $\begin{array}{c}\text { Specimen } \\
\text { number }\end{array}$ & $\begin{array}{l}\text { Matching } \\
\text { number }\end{array}$ & $\begin{array}{l}\text { Initial collapse } \\
\text { time } / \mathrm{min}\end{array}$ & $\begin{array}{l}\text { Periodic } \\
\text { collapse } \\
\text { time/min }\end{array}$ \\
\hline P01 & 582 & 15 & 8 & P23 & 764 & 15 & 9 \\
\hline P02 & 573 & 16 & 8 & P24 & 755 & 15 & 9 \\
\hline P03 & 564 & 21 & 11 & P31 & 882 & 12 & 5 \\
\hline P04 & 555 & 25 & 13 & P32 & 873 & 13 & 6 \\
\hline P11 & 682 & 13 & 6 & P33 & 864 & 14 & 6 \\
\hline P12 & 673 & 14 & 7 & P34 & 855 & 16 & 8 \\
\hline P13 & 664 & 15 & 8 & P41 & 982 & 11 & 4 \\
\hline P14 & 655 & 18 & 9 & P42 & 973 & 12 & 5 \\
\hline P21 & 782 & 12 & 6 & P43 & 964 & 13 & 6 \\
\hline P22 & 773 & 13 & 7 & P44 & 955 & 15 & 7 \\
\hline
\end{tabular}

The first collapse is simulated when the whole box is filled with mixture at both ends, the periodic collapse is simulated when the mixture is not filled at one end. To eliminate friction, a layer of lubricating oil is placed on the bottom of the experimental box, a film is placed, and the material is laid out in different proportions in the experimental box, compacted, and placed in ventilated and dry conditions for two days (due to the mining of the bottom coal seam, the separation between the top coal and the direct roof occurs immediately. The top coal will only bear self-weight, so it does not need to apply the load). Then, the drawing length will be determined according to the simulated mining progress, and the initial collapse time will be delayed by 20 minutes after mining. The periodic collapse time delayed by 10 minutes after mining is in accordance with the requirement, and selected by experiment. When the mass ratio is 5:6:4, the experiment requirement can be satisfied.

\section{2) Experimental layout and displacement} observation

Observe the three laws of similarity and plan simulation test, the similarity ratio is $1: 200$, the design model size is $190 \mathrm{~cm} \times 22 \mathrm{~cm}$, the height is $120 \mathrm{~cm}$. leave $20 \mathrm{~cm}$ pillar on the left and right sides, marked with latitude and longitude ink line in the model surface, the grid line size is $10 \mathrm{~cm} \times 10 \mathrm{~cm}$, while at the intersection of some of the grid into the pin as a displacement observation point. A total of 10 survey lines were arranged $(10 \mathrm{~cm}, 20 \mathrm{~cm}, 30 \mathrm{~cm}, 40 \mathrm{~cm}, 50 \mathrm{~cm}, 60 \mathrm{~cm}, 70$ $\mathrm{cm}, 80 \mathrm{~cm}, 90 \mathrm{~cm}, 100 \mathrm{~cm}$ ) above the coal seam floor, respectively, as shown in Figure 3. 


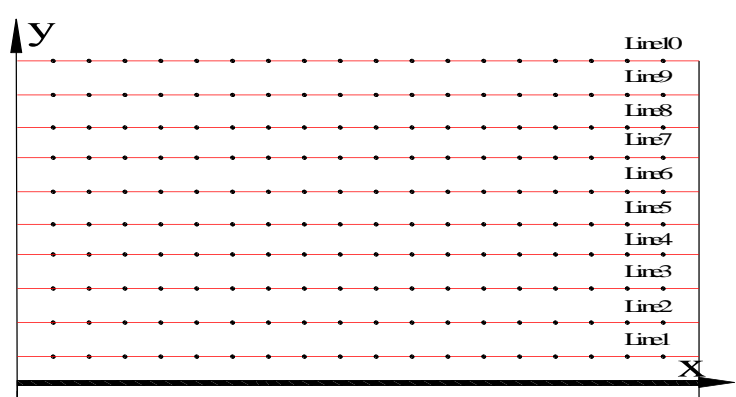

Fig.3 Displacement monitoring grid observation system

The effect after mining is shown in Figure 4. The change of position of each measuring point is observed regularly by using total station. The statistical results are shown in Figure 5.

The first step distance of coal seam roof is $43 \mathrm{~m}$, and the average periodic interval is $15 \mathrm{~m}$. When the coal seam is finished, the strata collapse from bottom to top, the height of rock collapse is $37 \mathrm{~m}$, the mature subsidence basin is formed on the surface with the maximum subsidence amount is $4030 \mathrm{~mm}$. Tensile crack appeared in the coal face wall and developed upward along the rock seam collapse angle, with an average collapse angle of $70^{\circ}$.

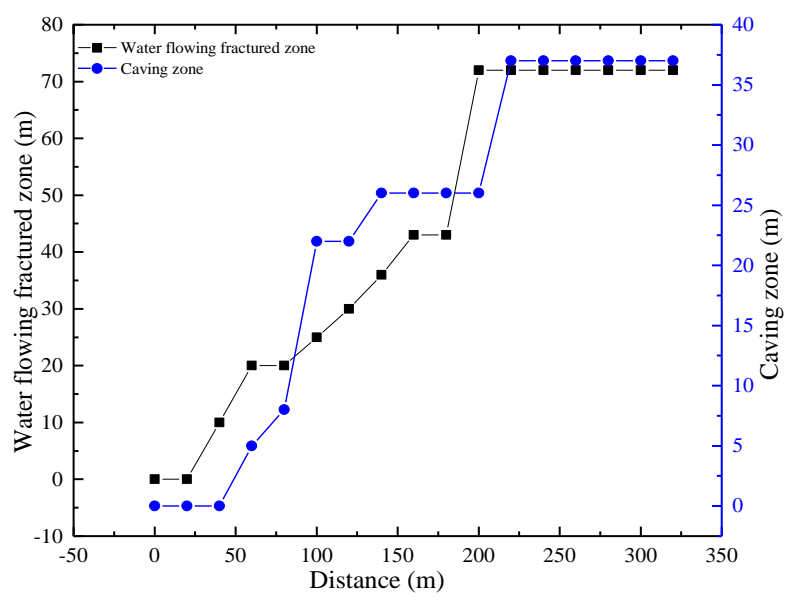

Fig.5 Water conduction fracture zone development

\section{3) Experimental analysis}

The thickness of the caving zone is larger, which is because the mining is thick and the mining time is short, the overburden space of the stope is large, and the roof rock formation in the upper layer is too late to whole sink. Therefore, it is necessary to fill the mining space with the dilatation volume of the falling rock block, thus increasing the height of the caving zone and increasing the whole collapse zone approximately straight line. Due

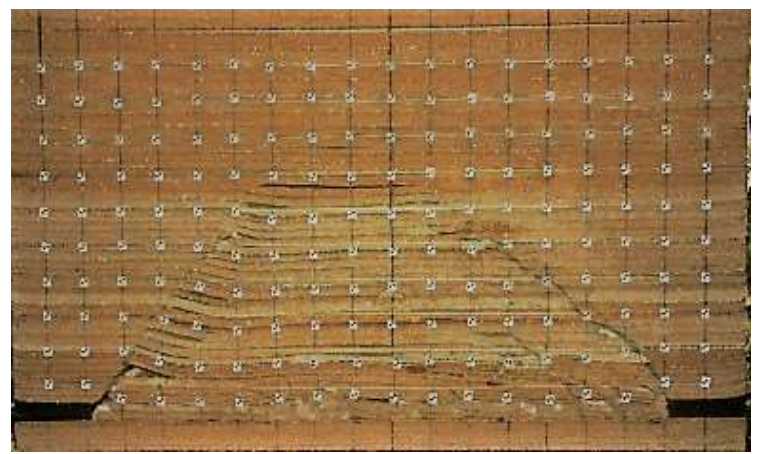

Fig.4 Model mining effect diagram

to the difference of the formation lithology, the development of the fractured zone of the water guide presents the characteristic of linear growth .Fissure developed into the soft rock mudstone of the Jurassic, the fissure development is temporarily inhibited, the coal seam continues to be mined $40 \mathrm{~m}$, and the height of the fracture is suddenly increased to the Jurassic hard rock sandstone. This stage can also be seen as the stage of fissure accumulation of energy, when the fissure accumulates more energy than the soft rock can absorb the energy, cracks through the soft rock, developed to the Jurassic hard rock sandstone. As the hard rock rupture also requires a lot of energy, and the upper layer of soft rock mudstone has this energy fully absorbed, it can not accumulate enough energy to make this layer of hard rock rupture, simulation results also confirmed this end.

\section{V.MEASUREMENT OF THE HEIGHT OF WATER FLOWING FRACTURED ZONE}

\section{A. Drilling layout}

According to the coal mine production layout, drilled hole in the middle of 3111 working face adjacent to the 3109 working face, used the upward hole with double end water blocking observation technology underground, Before the monitoring hole is arranged, the mining practice and the observation requirement of 3109 face should be considered synthetically. The measuring site of the height of water flowing fractured zone is selected at the crossheading of the 3109 working face auxiliary haulage gateway with 3110 working face belt haulage gateway, three observation holes are arranged altogether. One pre-mining observation hole, two post-harvest observation holes. The parameters of the three holes are shown in Table V, The location of the observation station is shown in Figure 6, the observation holes in the section are shown in Figure 7 , and the observation results are shown in Figure 8, 9, 10. 


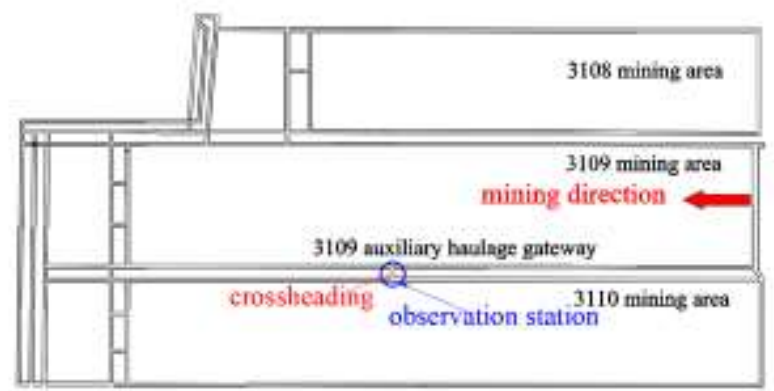

Fig. 6 Observation station position

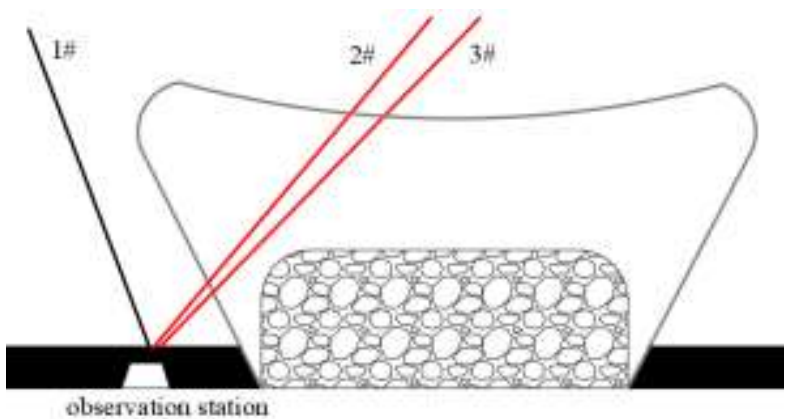

Fig. 7 Observation hole layout profile

TABLE V. DRILLING CONSTRUCTION ELEMENTS

\begin{tabular}{|c|c|c|c|c|c|c|}
\hline Hole number & Name & Aperture (mm) & Position & Elevation angle & Hole deep (m) & Complete time \\
\hline $1 \#$ & $\begin{array}{l}\text { Pre-mining } \\
\text { hole }\end{array}$ & 89 & $\mathrm{~N} 34^{\circ}$ & $55^{\circ}$ & 150 & not affected by mining \\
\hline $2 \#$ & $\begin{array}{c}\text { Post-mining } \\
\text { hole }\end{array}$ & 89 & $\mathrm{~N} 284^{\circ}$ & $45^{\circ}$ & 160 & a month after mining \\
\hline $3 \#$ & $\begin{array}{c}\text { Post-mining } \\
\text { hole }\end{array}$ & 89 & $\mathrm{~N} 314^{\circ}$ & $45^{\circ}$ & 160 & a month after mining \\
\hline
\end{tabular}

\section{B. Analysis of borehole leakage}

The leakage observation results of pre-mining hole (No. 1) is shown in Fig. 8 that there are basically a small amount of leakage in the whole hole section, especially the shallow part, the leakage amount is larger due to the existence of the primary fissure and the mining of the adjacent working face. The leakage amount is stable at about $1 \mathrm{~mL} / \mathrm{min}$, due to changes in rock lithology slightly fluctuations, and finally in the drilling depth of $95 \mathrm{~m}$ position, there is no leakage of drilling.

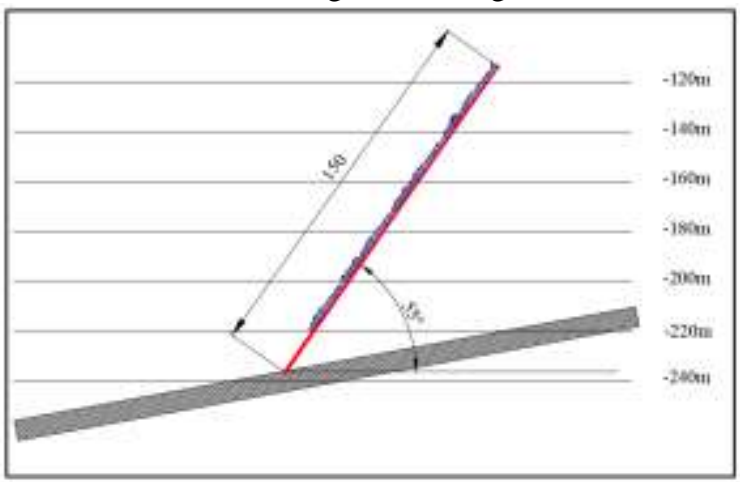

Fig. 8 Vertical profile of pre-mining hole (No. 1)

The leakage observation results of post-mining hole (No. 2) is shown in Fig. 9. During the whole observation period, the leakage experienced the process of stabilization, sudden increase, sudden decrease and dynamic stability, which indicated that the roof strata in the position of the boreholes were affected by the mining activities at different depths and were destroyed to different degrees. This can be seen from the different depth and size of the borehole water injection leakage can be seen. Through analysis, it can be seen that there is a large fractured area in the $10 \mathrm{~m}-48 \mathrm{~m}$ stage, and no or only a small amount of reverse water is found in the drilling process. It is also proved that the leakage in this area is reduced at the stage of $48 \mathrm{~m}-115 \mathrm{~m}$ with a large fissure, but the leakage is decreased. Compared with the pre-mining hole, the leakage is still relatively large. Therefore, the height of caving zone is about $34 \mathrm{~m}$, and the height of water-conducting fissure zone is $82 \mathrm{~m}$.

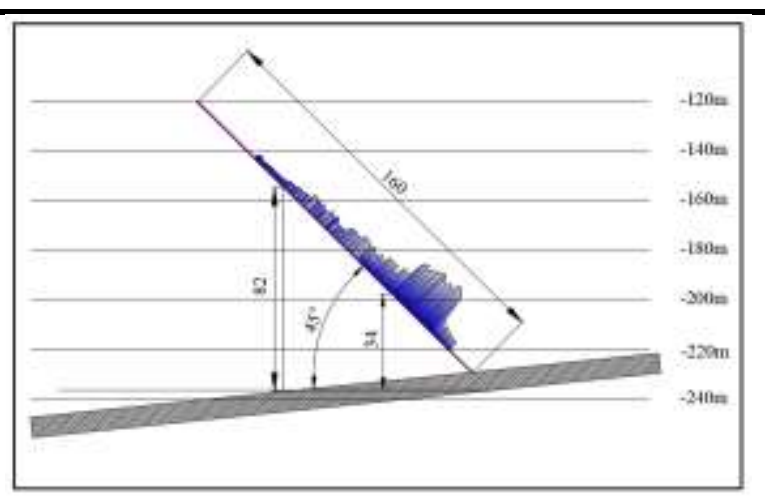

Fig. 9 Vertical profile of post-mining hole (No. 2)

The leakage observation results of post-mining hole (No. 3) is shown in Fig. 10. In the whole observation stage, the leakage has experienced the process of stabilization, sudden increase, sudden decrease and dynamic stability, as is the case with the borehole No. 2 drilling after mining. It can be seen from the analysis that there is a large fissure area in the $12-50 \mathrm{~m}$ stage and that there is no or only a small amount of reverse water in the drilling process. It is also proved that the leakage in this area is reduced in the period of $50 \mathrm{~m}$ and $118 \mathrm{~m}$, but compared with the pre-mining hole, it is also proved that there is a large fractured area at the stage of $50 \mathrm{~m}-118 \mathrm{~m}$. The leakage is still relatively large. Therefore, the height of the caving zone observed in the post-mining hole is about $40 \mathrm{~m}$, and the water flowing fractured zone height is $80 \mathrm{~m}$, compared with the post-harvest hole in $2 \#$, the leakage is basically the same.

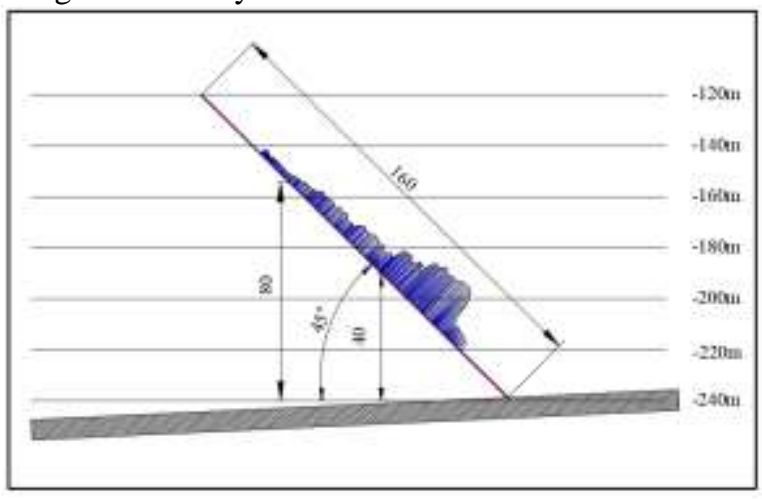

Fig. 10 Vertical profile of post-mining hole (No. 3) 
Because the bottom end of borehole is not the roof of 3109 working face, and there is $8 \mathrm{~m}$ thick coal seam, at the same time, the inclined angle of coal seam should be taken into account, then the height of water diversion fissure zone of 3109 face should be $75.05 \mathrm{~m}$. In summary, the measured height of caving zone is about $34 \mathrm{~m}$, and the height of water flowing fractured zone is $75.05 \mathrm{~m}$. By comparing the predicted results, it is found that the empirical formula calculation and analogy method both include the measured results, the prediction is basically accurate, but the accuracy is not high. Only the predicted results by combining the relevant rock pressure theory with the theoretical analysis of specific formation conditions in coal mines are accurate. The measured height of coal mine is $75.05 \mathrm{~m}$, which is $3.3 \mathrm{~m}$ higher than that predicted by theoretical analysis, which is caused by the disturbance at the bottom of thick hard rock.

Due to the existence of many factors, the accuracy of the results is not good enough. It can only be used as the reference data of the overburden fractures in coal mines. In order to accurately reflect the development of the fractures, the calculation of the empirical formula of the water flowing fractured zone and the calculation of the predicted results by the analogy method can only be used as the reference data. It must be analyzed in combination with specific geological occurrence conditions, and must be verified by field observation. However, the predicted results can provide reference data for the angle and depth of borehole arrangement, save manpower and material resources, and help to obtain accurate observation results.

\section{CONCLUSION}

(1) By comparing the predicted results, it is found that both the empirical formula calculation and the analogical prediction result include the measured results, but the accuracy is not high and the error is relatively large. The prediction results obtained by the empirical formula are generally applicable to the mining mode for the blasting mining and the ordinary mining. The results obtained by the analogical prediction are more limited because of the different mining thickness and geological conditions. Rock pressure theory combined with the theoretical analysis of the specific formation conditions of coal mines can meet the requirements of coal mining protection because of the minimum error of the predicted results.

(2) In order to more reasonably and effectively simulate the overlying rock movement and the damage characteristics of the fully mechanized caving mining field, a small experimental box is made to simulate the falling time of the simulated materials under different proportions, and the simulated materials with reasonable strength of coal gangue, sand and cementation are obtained, thus effectively simulating the water conducting fissure zone under the condition of fully mechanized caving in Xin'an coal mine, it provides a scientific and reliable basis for the prevention and control of water damage in the fully mechanized caving face under the shallow Quaternary loose stratum, the raising of the upper limit of mining and the realization of safe production.
(3) The development height of the water-conducting fissure zone is measured by the monitoring system. The leakage has experienced the process of stabilization, sudden increase, sudden decrease and dynamic stability. The damage degree of the water conducting fissure zone is not smaller as the distance is farther away the working face, but it is related to the properties of the rock strata in various positions, showing a different degree of damage.

\section{REFERENCES}

[1] L. Tianquan, "Safe mining of near loose layer under thick unconsolidated aquifer," Coal science and technolog, vol. 13, pp. 14-18, 1986.

[2] State Bureau of Coal Industry. "Standard Practice for the construction of coal pillars and coal pillars for buildings, water bodies, railways and main wells," Beijing:China Coal Industry Publishing House, pp.38-43, 2000.

[3] X. Jialin, Z. weibing, W. Xiaozhen. "Prediction method of water flowing fractured zone height based on key stratum position," Journal of China Coal Society, vol. 37, pp.14-18, 762-769, 2009.

[4] X. Jialin, W. Xiaozhen, L. Wentao, W. Zhigang. "The influence of the location of the main key stratum on the height of water flowing fractured zone," Chinese Journal of rock mechanics and Engineering, vol. 28, 380-385, 2009.

[5] W. Lianguo, W. Zhansheng, H Jihui, Z Donglei. "Prediction of the height of water flowing fractured zone in shallow coal seam with thin bedrock and thick aeolian sand," Journal of mining \& safety engineering, vol. 29, pp.607-612, 2012.

[6] H. Wanpeng, G. Yanfa, W. Bo, L. Jiren. "Evolution rule and development height of permeable fractured zone under combined-strata structure," Journal of Mining \& Safety Engineering, vol. 2, pp330-335, 2017.

[7] Z. Jianmin, Zhang Kai, Cao Zhiguo, et al. "Study on mining-bursting simulation and height calculation method for conducting-water fractured zone," Journal of China Coal Society, vol. 42, pp.1557-1564, 2017.

[8] C. Huabin, Z. Junpeng, Y. Chao. "Prediction of water-flowing height in fractured zone of overburden strata based on GA-SVR," Journal of Mining \& Safety Engineering, vol. 35, :pp359-365, 2018.

[9] S. Zhang, L. Yin.“ A Simple and Efficient Way to Detect the Mining Induced Water-conducting Fractured Zone in Overlying Strata," Energy Procedia, vol. 16: pp. 70-75, 2012.

[10] X. Miao, C. Ximin, W. Jin'an, X. Jialin. "The height of fractured water-conducting zone in undermined rock strata," Engineering Geology, vol. 120: pp. 32-39, 2011.

[11] X. Liu, T.Yunliang, N. Jianguo, T. Chenlin, W. Jun. "The Height of Water-Conducting Fractured Zones in Longwall Mining of Shallow Coal Seams," Geotech Geol Eng, 2015.

[12] M. Zhang, J. Ning. "The Influence of Mining Height on the Height of Water Flowing Fractured Zone," Advanced Materials Research, pp. 481-484, 2012.

[13] W. Yucheng, W. Changxiang, M. "Wenqiang. Prediction of height of water flowing fractured zone in overlying mining," Coal Technology, vol 6: pp 181-183, 2015.

[14] T. Jiajia, W. Changxiang, L. Jinping, J. Ning, Z. Shichuan. "Simulation study on spatial characteristics and development mechanism of water flowing fracture in shallow soft rock thick coal seam," Coal Technology, vol 5: pp 66-68, 2016.

[15] W. Linlin, W. Jiuchuan, Y. Huiyong, X. Daolie. "Study on the height of water flowing fractured zone of 16 coal seam in Xin'an coal mine," Journal of Shandong University of Science and Technology(Natural Science), vol 1: pp40-45, 2014.

[16] N. Xinghua, Z. Yuanren, X. Yeliang, Z. Wenquan, L. Weitao. "The fully mechanized top coal caving working face overburden caving zone height observation," Coal Mining Technology, vol S1:53-57, 1996

[17] Z. Wenquan. "Surfaces of Nantun Coal Mine fully mechanized top coal caving mining overburden failure and deformation characteristics of mobile," Journal of Shandong Mining Institute, vol 4:24-28+38, 1996

[18] S. Zhenqi. "Practical mine pressure control". Xuzhou: China University of Mining and Technology press, 1988 
[19] W. Changxiang. "An experimental box for measuring the breaking expansion coefficient of broken roof simulated materials". Shandong: CN205139135U,2016-04-06. 